\title{
РАСПРОСТРАНЕННОСТЬ ВОЗБУДИТЕЛЕЙ ГНОЙНЫХ ХИРУРГИЧЕСКИХ ИНФЕКЦИЙ В РЕГИОНАЛЬНОЙ КЛИНИЧЕСКОЙ БОЛЬНИЦЕ ГОРОДА ДОДОМЫ ОБЪЕДИНЕННОЙ РЕСПУБЛИКИ ТАНЗАНИИ И ИХ ЧУВСТВИТЕЛЬНОСТЬ К АНТИБАКТЕРИАЛЬНОЙ ТЕРАПИИ
}

\author{
(C) Антонов A.E. ${ }^{1}$, Гесасе $A . \Pi^{2}$, Млова В. ${ }^{3}$ \\ ${ }^{1}$ Кафедра хирургических болезней факультета последипломного образования \\ Курского государственного медицинского университета, Курск; \\ ${ }^{2}$ Колледж наук о здоровье Университета Додомы, Додома, Танзания; \\ ${ }^{3}$ Региональная клиническая больница Додомы, Додома, Танзания \\ E-mail: drantonov@,mail.ru
}

\begin{abstract}
Исследование посвящено эпидемиологии микроорганизмов, ответственных за развитие гнойных хирургических инфекций у больных, проходивших лечение в крупном государственном клиническом стационаре - Региональной клинической больнице Додомы, Танзания, в ноябре 2014 - марте 2015 г, а также изучению носительства оппортунистических микроорганизмов среди медсестер. Было проведено определение чувствительности выделенных возбудителей к распространенным антибактериальным препаратам. Статья содержит анализ соответствия лекарственных средств, первично назначенных пациентам, результатам определения чувствительности флоры, полученных в микробиологических исследованиях. Были предприняты попытки выявить возбудителей - кандидатов на роль факторов внутрибольничных инфекций. Представлен набор практических рекомендаций для исследуемого стационара, направленных на предупреждение циркуляции таких инфекционных агентов среди пациентов и медперсонала.
\end{abstract}

Ключевые слова: гнойные хирургические инфекции, внутрибольничные инфекции, нозокомиальные инфекции, оппортунистические инфекции, госпитальный штамм, антибактериальная терапия, медицина в Африке.

\section{PREVALENCE OF VARIOUS PATHOGENS CAUSING SEPTIC SURGICAL INFECTIONS IN DODOMA REGIONAL REFERRAL HOSPITAL AND THEIR ANTIBACTERIAL SENSITIVITY Antonov A.E. ${ }^{1}$, Gesase A.P. ${ }^{2}$, Mlowa . $^{3}$}

${ }^{1}$ Department of Surgical Diseases of Postgraduate Education Faculty of Kursk State Medical University, Kursk;

${ }^{2}$ College of Health Sciences of University of Dodoma, Dodoma, Tanzania;

${ }^{3}$ Dodoma Regional Referral Hospital, Dodoma, Tanzania

The study investigates epidemiology of microorganisms, responsible for the development of septic surgical infections in sick persons who underwent inpatient treatment in a large referral state hospital - Dodoma Regional Hospital, Tanzania in November 2014 - March 2015 as well as nurses' carriage of opportunistic pathogens. The assessment of isolated microorganisms' sensitivity to common antibacterial agents was conducted. The study included analysis of the consistency of drugs initially administered for the patients' treatment (therapia ex juvantibus) to the results of microbiological sensitivity tests. The study attempted to select candidates for the role of nosocomial infections in the hospital. The list of practical recommendations was developed for the prevention of the circulation of such infectious agents among patients and medical staff.

Keywords: suppurative surgical infections, hospital-acquired infections, nosocomial infections, opportunistic pathogens, hospital strain, antibacterial treatment, medicine in Africa.

Правильный выбор антибактериальных препаратов для лечения хирургических больных является одной из наиболее актуальных проблем биологической антисептики, поскольку от него зависит эффективность лечения и вероятность развития побочных эффектов. Ошибка в выборе антибиотика приводит к повышению резистентности микроорганизмов к этим веществам [2, 4] и вынуждает хирургов применять новые и более дорогие лекарства, увеличивая стоимость лечения [3]. Выбор лекарственного средства предполагает слаженное сотрудничество хирургического отделения и микробиологической лаборатории. Тем не менее во многих больницах результаты микробиологических исследований могут быть получены не ранее чем через три дня после госпитализации и взятия материала для анализа [1]. Это означает, что пациентам в течение нескольких дней антибактериальное лечение должно подбираться эмпирически или на основании результатов исследований о распространенности тех или иных видов микроорганизмов в стационаре или регионе [5]. Вместе с тем подобных исследований в столичном регионе Додомы не проводилось. Изложенное определяет важность выявления наиболее часто встречающихся микроорганизмов, характерных для пациентов, проходящих стационарное лечение в крупнейшем стационаре Додомы - Региональной клинической больнице. 
Целью нашего исследования явилось определение распространенности различных видов микроорганизмов, вызывающих нагноительные хирургические заболевания в Региональной клинической больнице Додомы, и изучение их чувствительности к распространенным антибактериальным препаратам.

Цели исследования:

1. Установить

распространенность микроорганизмов у больных, проходящих стационарное лечение по поводу гнойных хирургических инфекций.

2. Установить распространенность микроорганизмов, персистирующих у медработников, оказывающих медицинскую помощь таким пациентам.

\section{МАТЕРИАЛЫ И МЕТОДЫ ИССЛЕДОВАНИЯ}

В исследовании приняли участие 43 пациента, проходивших стационарное лечение в Региональной клинической больнице Додомы по поводу гнойных хирургических инфекций в период с ноября 2014 года по март 2015 года, и 8 медсестер, оказывавших медицинскую помощь в профильных отделениях. Поскольку отказов от участия в исследовании не было, отбор проб был произведен у 100\% пациентов и медицинских сестер, которые лечились или работали в течение этого периода в указанных палатах.

Материал (раневые мазки у пациентов и мазки из носовых ходов у медработников) собирался одним исследователем в асептических условиях с помощью стерильного тампона и направлялся в микробиологическую лабораторию больницы в контейнерах с транспортной средой Стюарта не позднее чем через 1 час после взятия.

Бактериологические и микробиологические исследования проводились одним специалистом и включали в себя определение вида возбудителя и его чувствительности к распространенным антисептикам и антибиотикам, из групп пеницилли- нов, цефалоспоринов, аминогликозидов, фторхинолонов, макролидов, линкозамидов и амфениколов.

Результаты исследования были статистически обработаны с использованием Microsoft ${ }^{\circledR}$ Office Excel c применением методов описательной статистики (средние значения, ошибки репрезентативности, критерий Стьюдента, статистическая значимость Р).

\section{РЕЗУЛЬТАТЫ ИССЛЕДОВАНИЯ И ИХ ОБСУЖДЕНИЕ}

Доля мужчин среди пациентов было значительно выше $(\mathrm{P} \leq 0,001)$, чем женщин $(62,8$ и $37,2 \%$ соответственно, $\mathrm{m}=7,4)$. Средний возраст больных составил $33,2(\mathrm{~m}=3,4)$ года. Структура заболеваемости среди пациентов, включенных в исследование, представлена в табл. 1.

Значительная доля больных $(44,2 \%)$ проходила лечение по поводу гнойных хирургических инфекций, осложнивших травмы или ранения (в т.ч. уколы колючками, типичные для той местности, ожоги, открытые переломы). У трех пациентов развились нагноения послеоперационных ран.

Доля пациентов, у которых антибактериальное лечение было начато до сбора материала (например, в случае переводов из других медицинских учреждений или самостоятельного лечения), составила 90,7\% $(\mathrm{m}=4,4)$. У остальных 9,3\% больных забор материала был сделан до первого введения антибактериальных препаратов.

Структура больных по наименованию антибиотиков и антисептиков, используемых для начального лечения (до получения результатов исследования на чувствительность), представлена в табл. 2.

Как видно из таблицы, наиболее часто назначаемым антибактериальным препаратом (за исключением антисептика Метронидазола) был Ампиклокс (Ампициллин + Клоксациллин), применявшийся у более чем двух третей пациентов.

Таблица 1

Распределение пациентов по группам заболеваний

\begin{tabular}{|l|c|c|}
\hline \multicolumn{1}{|c|}{ Группы заболеваний } & \multicolumn{2}{c|}{ Доли пациентов $(\mathrm{n}=43)$} \\
\cline { 2 - 3 } & $\mathrm{p}, \%$ & $\mathrm{~m}, \%$ \\
\hline Открытые переломы и огнестрельные ранения & 16,3 & 5,6 \\
\hline Прочие случайные раны & 23,3 & 6,4 \\
\hline Нагноившиеся послеоперационные раны & 7,0 & 3,9 \\
\hline Инфекции мягких тканей (абсцессы, флегмоны и др.) & 16,3 & 5,6 \\
\hline Ожоги & 11,6 & 4,9 \\
\hline Распадающиеся злокачественные опухоли & 4,7 & 3,2 \\
\hline Диабетическая стопа & 4,7 & 3,2 \\
\hline Прочие & 16,3 & 5,6 \\
\hline
\end{tabular}


Таблица 2

Распределение пациентов по наименованиям антибактериальных препаратов, назначенных для системного лечения до получения результатов микробиологического исследования

\begin{tabular}{|c|c|c|}
\hline \multirow{2}{*}{ Антибиотики/антисептики } & \multicolumn{2}{|c|}{ Доли пациентов (n = 39) } \\
\hline & $\mathrm{p}, \%$ & $\mathrm{~m}, \%$ \\
\hline \multicolumn{3}{|l|}{ Антисептики } \\
\hline Метронидазол & 74,4 & 7,0 \\
\hline \multicolumn{3}{|l|}{ Пенициллины } \\
\hline Ампициллин & 7,7 & 4,3 \\
\hline Клоксациллин & 5,1 & 3,5 \\
\hline Ампиокс (Ампициллин + Оксациллин) & 2,6 & 2,5 \\
\hline Ампиклокс (Ампициллин + Клоксациллин) & 56,4 & 7,9 \\
\hline Амоксициллин & 2,6 & 2,5 \\
\hline $\begin{array}{l}\text { Итого, один или более одного антибиотика } \\
\text { группы пенициллинов }\end{array}$ & 69,2 & 7,4 \\
\hline \multicolumn{3}{|l|}{ Цефалоспорины } \\
\hline Цефтриаксон & 30,8 & 7,4 \\
\hline \multicolumn{3}{|l|}{ Аминогликозиды } \\
\hline Гентамицин & 15,4 & 5,8 \\
\hline \multicolumn{3}{|l|}{ Фторхинолоны } \\
\hline Норфлоксацин & 7,7 & 4,3 \\
\hline \multicolumn{3}{|l|}{ Макролиды } \\
\hline Эритромицин & 5,1 & 3,5 \\
\hline Итого, назначено более одного антибиотика & 87,2 & 5,4 \\
\hline
\end{tabular}

Таблица 3

Распределение пациентов по видовой принадлежности микроорганизмов

\begin{tabular}{|c|c|c|}
\hline \multirow{2}{*}{ Виды микроорганизмов } & \multicolumn{2}{|c|}{ Доли пациентов (n = 38) } \\
\hline & $\mathrm{p}, \%$ & $\mathrm{~m}, \%$ \\
\hline \multicolumn{3}{|l|}{ Грамположительные } \\
\hline Staphylococcus spp., кроме S. aureus & 23,7 & 6,9 \\
\hline Staphylococcus aureus & 7,9 & 4,4 \\
\hline Иные грамположительные & 2,6 & 2,6 \\
\hline Итого, 1 или более вид грамположительных микроорганизмов & 34,2 & 7,7 \\
\hline \multicolumn{3}{|l|}{ Грамотрицательные } \\
\hline Proteus spp. & 15,8 & 5,9 \\
\hline Бактерии группы кишечной палочки, кроме E. coli & 21,1 & 6,6 \\
\hline E. coli & 13,2 & 5,5 \\
\hline Pseudomonas aeruginosa & 15,8 & 5,9 \\
\hline Klebsiella spp. & 5,3 & 3,6 \\
\hline Иные грамотрицательные & 2,6 & 2,6 \\
\hline Итого, 1 или более вид грамотрицательных микроорганизмов & 68,4 & 7,5 \\
\hline \multicolumn{3}{|l|}{ Смешанные } \\
\hline Грамположительные + грамотрицательные & 2,6 & 2,6 \\
\hline Грамотрицательные + грамотрицательные & 5,3 & 3,6 \\
\hline Итого, смешанные & 7,9 & 4,4 \\
\hline
\end{tabular}

Лечащие врачи избрали тактику одновременного системного применения более одного лекарственного средства в подавляющем большинстве случаев $(87,2 \%)$. При этом системное лечение одного пациента (2,6\%, $\mathrm{m}=2,5)$ включало в себя четыре антибактериальных препарата, лечение семи $(17,9 \%$, $\mathrm{m}=6,1)-$ трех веществ. Одновременное или последовательное назначение двух препаратов, относящихся к группе пенициллинов, было выявлено у двух больных $(5,1 \%, \mathrm{~m}=5,1)$. Полученные данные указывают на большие трудности, с которыми сталкиваются медицинские работники в выборе эффективных 
антибактериальных препаратов. Вынужденная полипрагмазия имеет очевидные негативные последствия - финансово-экономические (рост расходов на лечение и увеличение продолжительности стационарного лечения) и клинические (потенцирование токсических эффектов препаратов и увеличение вероятности побочных эффектов). Такая стратегия также способствует росту резистентности микроорганизмов, в т.ч. сапрофитных бактерий.

В пяти случаях микробиологических исследований $(11,6 \%, \mathrm{~m}=4,9)$ роста флоры на используемых средах не было. Распределение остальных пациентов по видам выделенных микроорганизмов представлено в табл. 3.

Как видно из таблицы, гнойные хирургические инфекций у большинства пациентов были вызваны грамотрицательными условно-патогенными микроорганизмами, которые были определены достоверно чаще $(\mathrm{m}=5,4, \quad \mathrm{P} \leq 0,001), \quad$ чем грамположительные. Однако наиболее распространенной причиной были организмы рода Staphylococcus, являющиеся грамположительными кокками. Доля Staphylococcus spp., кроме S. aureus, среди общего числа грамположительных патогенных микроорганизмов достигла 69,2\%, $\mathrm{m}=12,8$.

Ocобое внимание следует обратить на значительную $(15,8 \%)$ долю синегнойной палочки в структуре видовой принадлежности возбуди- телей. Этот микроорганизм часто является причиной внутрибольничных инфекций. Pseudomonas aeruginosa быстро приобретает устойчивость к антибактериальным препаратам. Ранние поколения цефалоспоринов и пенициллинов не достаточно эффективны в ее отношении. Смешанные инфекции имели место в трех случаях, а именно: E. coli + Klebsiella spp. и E. coli + Proteus spp. В третьем случае имела место комбинация грамположительного и грамотрицательного микроорганизмов, точная видовая принадлежность которых не была определена.

Данные о чувствительности выделенных микроорганизмов к распространенным антибактериальным препаратам представлены в табл. 4.

Особо следует отметить, что отсутствие устойчивости к противомикробным веществам было обнаружено только у одного пациента $(2,6 \%, \mathrm{~m}=2,6)$. Резистентность к одному или нескольким представителям одной группы препаратов было выявлена в 28,9\% $(\mathrm{m}=7,4)$ случаев, двух групп - в 36,8\% $(\mathrm{m}=7,8)$, трех - в $23,7 \%(\mathrm{~m}=6,9)$, и большего числа лекарственных групп - у 7,9\% $(\mathrm{m}=4,4)$ больных. Выявлен один клинический случай, в котором микроорганизмы, выделенные из организма пациента, продемонстрировали устойчивость к представителям пяти групп антисептиков и антибиотиков одновременно.

Таблица 4

Распределение возбудителей по степени чувствительности к антибактериальным препаратам

\begin{tabular}{|c|c|c|c|c|c|c|}
\hline \multirow{3}{*}{ Антибиотики/антисептики } & \multicolumn{6}{|c|}{ Степени чувствительности } \\
\hline & \multicolumn{2}{|c|}{ Устойчивы } & \multicolumn{2}{|c|}{ Умеренно чувствительны } & \multicolumn{2}{|c|}{ Чувствительны } \\
\hline & $\mathrm{p}, \%$ & $\mathrm{~m}, \%$ & $\mathrm{p}, \%$ & $\mathrm{~m}, \%$ & $\mathrm{p}, \%$ & $\mathrm{~m}, \%$ \\
\hline \multicolumn{7}{|l|}{ Антисептики } \\
\hline Метронидазол & 100,0 & 0,0 & 0,0 & 0,0 & 0,0 & 0,0 \\
\hline $\begin{array}{l}\text { Ко-тримоксазол } \\
\text { (Сульфаметоксазол + Триметоприм) }\end{array}$ & 92,3 & 7,4 & 0,0 & 0,0 & 7,7 & 7,4 \\
\hline \multicolumn{7}{|l|}{ Пенициллины } \\
\hline Ампициллин & 92,3 & 5,2 & 3,8 & 3,8 & 3,8 & 3,8 \\
\hline $\begin{array}{l}\text { Амоксиклав (Амоксициллин + } \\
\text { Клавулановая кислота) }\end{array}$ & 84,0 & 7,3 & 4,0 & 3,9 & 12,0 & 6,5 \\
\hline \multicolumn{7}{|l|}{ Цефалоспорины } \\
\hline Цефазолин & 100,0 & 0,0 & 0,0 & 0,0 & 0,0 & 0,0 \\
\hline Цефтазидим & 66,7 & 19,2 & 0,0 & 0,0 & 33,3 & 19,2 \\
\hline \multicolumn{7}{|l|}{ Аминогликозиды } \\
\hline Гентамицин & 45,5 & 8,7 & 6,1 & 4,2 & 48,5 & 8,7 \\
\hline \multicolumn{7}{|l|}{ Фторхинолоны } \\
\hline Ципрофлоксацин & 10,8 & 5,1 & 5,4 & 3,7 & 83,8 & 6,1 \\
\hline \multicolumn{7}{|l|}{ Линкозамиды } \\
\hline Клиндамицин & 18,2 & 11,6 & 18,2 & 11,2 & 63,6 & 14,5 \\
\hline \multicolumn{7}{|l|}{ Макролиды } \\
\hline Эритромицин & 83,3 & 15,2 & 0,0 & 0,0 & 16,7 & 15,2 \\
\hline \multicolumn{7}{|l|}{ Амфениколы } \\
\hline Хлорамфеникол & 12,5 & 6,8 & 12,5 & 6,8 & 75,0 & 8,8 \\
\hline
\end{tabular}


В целом антибактериальная устойчивость микроорганизмов к представителям двух или более групп препаратов является характерной для больных в Региональной клинической больнице Додомы и встречается в $68,4 \%, \mathrm{~m}=7,5$ случаев.

Как видно из таблицы, наиболее эффективный препарат для лечения инфекций, выделенных в стационаре, был Ципрофлоксацин. Только $16,2 \% \quad(\mathrm{~m}=6,1) \quad$ возбудителей были стойкими или умеренно чувствительными к нему. Хлорамфеникол может также считается весьма эффективным средством, так как только четверть $(25 \%, \mathrm{~m}=8,8)$ микроорганизмов была устойчива или умеренно чувствительна к нему.

Полная устойчивость к Метронидазолу является тревожным фактом. Важность этого наблюдения обусловлена сложившейся в Региональной клинической больнице Додомы практикой применения этого вещества для местного лечения раневой инфекции. Препарат применялся у более чем $90 \%$ больных с гнойными хирургическими инфекциями. Ампициллин, а также комплексные препараты, содержащие это вещество, использовались в лечении значительной $(68,4 \%, \mathrm{~m}=7,5)$ части больных. В то же время устойчивость или умеренная чувствительность к нему была выявлена у $53,8 \%(\mathrm{~m}=9,8)$ пациентов.

Три случая гнойных хирургических инфекций у женщин (проходящих лечение в одной женской палате) были вызваны синегнойной палочкой. Была обнаружена идентичность спектра чувствительности выделенных у них микроорганизмов. Этот факт позволяет рассматривать эти микроорганизмы в качестве возможного возбудителя госпитальной инфекции. Важно отметить, что существовала другая раса синегнойной палочки, обнаруженная в мужской палате. Эти микроорганизмы также обладали одинаковым спектром антибактериальной чувствительности, но отличались по этому свойству от расы возбудителя из женской палаты. Например, Pseudomonas aeruginosa в женской палате были чувствительны к Гентамицину и Цефтазидиму, а бактерий этого вида из мужского отделения были устойчивы к обоим этим антибиотикам. Мужские и женские палаты для больных с гнойными хирургическими инфекциями в Региональной клинической больнице Додомы представляют собой отделенные здания, что работает как изолирующий фактор и препятствует перекрестному распространению инфекций между ними. Тем не менее окончательное подтверждение связи данного наблюдения с наличием внутрибольничной инфекции в палатах требует проведения генетического сравнения микроорганизмов $\mathrm{c}$ помощью полимеразной цепной реакции, что не было сделано по причине отсутствия технической возможности.
Обследование среднего медицинского персонала, участвующего в лечении пациентов, дало следующие результаты. Доля женщин составила $75 \%$, мужчин - 25\% $(\mathrm{m}=16,4)$. Средний возраст составил 43,9 лет $(\mathrm{m}=5,2)$. Все медицинские работники на момент проведения исследования были относительно здоровыми и не предъявляли жалоб. Сотрудники не принимали каких-либо антибактериальных препаратов в течение по крайней мере двух недель до взятия материала.

Золотистый стафилококк был выделен в двух случаях $(28,6 \%$ от выделенных микроорганизмов), другие виды рода Staphylococcus - у пяти сотрудников $(71,4 \%)$. В одном случае рост на использовавшихся средах отсутствовал. Все стафилококки из обеих групп были устойчивы к Метронидазолу и Эритромицину.

Выделенный золотистый стафилококк был чувствителен к Ампициллину, Ципрофлоксацину, Клиндамицину и Хлорамфениколу и устойчив или умеренно чувствителен к Гентамицину. Staphylococcus aureus, выделенный у двух пациентов, обладал сходным спектром чувствительности. Это наблюдение может служить аргументом в пользу предположения о том, что в больнице присутствует циркуляция этого возбудителя. Для окончательного подтверждения этого предположения также требуется проведение полимеразной цепной реакции.

Staphylococcus других видов, выделенные у медицинских работников, не демонстрировали сходных спектров чувствительности. Как правило, эти стафилококки были чувствительны (в одном случае умеренно чувствительны к Хлорамфениколу), чувствительны (в одном случае умеренно чувствительны) к Ципрофлоксацину. Около половины возбудителей этой группы были чувствительны к Гентамицину и Клиндамицину.

Установлено, что отсутствие устойчивости к противомикробным веществам не было обнаружено ни у одного сотрудника. Устойчивость к одному или нескольким представителям одной группы противо-микробных препаратов была обнаружена в одном случае - в $14,3 \%(\mathrm{~m}=13,2)$, двух групп - в $42,9 \%(m=18,7)$, трех - в $42,9 \%$ $(\mathrm{m}=18,7)$. В целом устойчивость к двум и более группам антибактериальных средств является характерной для условно-патогенных микроорганизмов выделенных у медработников стационара и встречается у $85,7 \%, \mathrm{~m}=13,2$ из них.

Полученные данные позволяют сделать следующие выводы:

1. Хирургические инфекции у большинства $(68,4 \%, m=7,5)$ пациентов, проходивших стационарное лечение в Региональной клинической 
больнице Додомы, были вызваны грамотрицательными условно-патогенными микроорганизмами, которые были выделены значительно $(\mathrm{m}=$ $5,4, \mathrm{P} \leq 0,001)$ чаще, чем грамположительные.

2. Множественная антибактериальная устойчивость является характерной для микроорганизмов, выделенных в ходе исследования, и встречалась у $68,4 \%, \mathrm{~m}=7,5$, больных с гнойно-хирургическими инфекциями и $85,7 \%, \mathrm{~m}=13,2$, медработников, участвующих в их лечении. Наиболее эффективными антибактериальными средствами для лечения больных были Ципрофлоксацин и Хлорамфеникол: чувствительность к ним была установлена в $83,8 \%, \mathrm{~m}=6,1$, и $75 \%, \mathrm{~m}=8,8$, случаев соответственно. Микроорганизмы, выделенные из гнойных очагов, демонстрировали наибольшую устойчивость к Метронидазолу и Цефазолину $(100,0 \%)$, Ко-тримоксазолу (Сульфаметоксазол + Триметоприм) - 92,3\%, $\mathrm{m}=7,4$, Ампициллину $-92,3 \%, m=5,2$, Амоксиклаву (Амоксициллин + Клавулановая кислота) $-84 \%, \mathrm{~m}=5,2$, Эритромицину $-83,3 \%, \mathrm{~m}=15,2$.

3. Три отдельные расы организмов могут рассматриваться в качестве кандидатов на фактор внутрибольничной инфекции (по одной расе синегнойной палочки в мужской и женской палатах и одна раса золотистого стафилококка, присутствовавшая у пациентов и медицинского персонала).

Исследование позволяет предложить следующие практические рекомендации:

1. Осуществлять отбор материала для микробиологического исследования и определения чувствительности патогенных микроорганизмов у всех пациентов, поступающих в Региональную клиническую больницу Додомы для лечения по поводу гнойных хирургических заболеваний, предпочтительно до начала антибактериальной терапии. Оптимизировать выбор антибиотиков для начальной терапии на основе представленных данных; исключить одновременное или последовательное введение двух или более антибиотиков, принадлежащих к той же группе; заменить антисептическое средство Метронидазол, используемый для местного и системного лечения, а также антибиотик Ампициллин, применяющийся системно, на другие антибактериальные средства, основывая выбор на результатах исследования чувствительности.

2. Рассмотреть возможность комплексных мер по борьбе с внутрибольничными инфекциями (провести капитальный ремонт палат, выделенных для лечения больных с гнойными хирургическими инфекциями; разобщить потоки пациентов, проходящих лечение в настоящий момент и вновь поступивших; провести профилактическое контролируемое лечение медицинского персонала; осуществлять допуск персонала к работе по результатам регулярно проводимых профилактических обследований, в том числе обязательного микробиологического тестирования; ограничить допуск посторонних лиц в палаты для лечения больных с гнойнохирургическими инфекциями; запустить процесс планового прямого контроля стерильности инструментов, перевязочных материалов и хирургического белья; организовать процесс перевязок пациентов с гнойными хирургическими инфекциями только в специально отведенных помещениях.

\section{ЛИТЕРАТУРА}

1. Classen D.C., Evans R.S., Pestotnik S.L., Horn S.D., Menlove R.L., Burke J.P. The timing of prophylactic administration of antibiotics and the risk of surgicalwound infection // The New England Journal of Medicine. - 1992. - Vol. 326. - P. 281-286.

2. Enright M., Robinson D., Randle G., Feil E., Grundmann $H$., Spratt $B$ The evolutionary history of methicillin-resistant Staphylococcus aureus (MRSA) // Proc Natl Acad Sci U S A. - 2002. - Vol. 99, N 11. P. 7687-7692.

3. Hawkey P.M. The growing burden of antimicrobial resistance // J Antimicrob Chemother. - 2008. Vol. 62, Suppl 1. - P. i1-9. - doi: 10.1093/jac/dkn241.

4. WHO's first global report on antibiotic resistance reveals serious, worldwide threat to public health [Электронный pecypc] // The World Health Organization, 2014. - Режим доступа: http://www.who.int/mediacentre/news/releases/2014/a mr-report/en/, свободный (07.04.2016).

5. Woods R.K., Dellinger E.P. Current guidelines for antibiotic prophylaxis of surgical wounds // American Family Physician. - 1998. - Vol. 57. - P. 2731-2740. 